\title{
Commentary \\ Fluid balance as a biomarker: impact of fluid overload on outcome in critically ill patients with acute kidney injury
} Sean M Bagshaw ${ }^{1}$, Patrick D Brophy² ${ }^{2}$ Dinna Cruz ${ }^{3}$ and Claudio Ronco ${ }^{3}$

\author{
${ }^{1}$ Division of Critical Care Medicine, Faculty of Medicine and Dentistry, University of Alberta, 3C1.12 Walter C Mackenzie Centre, 8440-112 ST NW, \\ Edmonton, T6G 2B7, Canada \\ 2Division of Nephrology, Hypertension, Dialysis and Transplantation, Department of Pediatrics, 285 Newton Road, 1269-A CBRB, lowa City, lowa, \\ 52242, USA \\ ${ }^{3}$ Department of Nephrology Dialysis \& Transplantation, San Bortolo Hospital, Viale Rodolfi 37, 36100 Vicenza, Italy
}

Corresponding author: Claudio Ronco, cronco@goldnet.it

Published: 24 July 2008

This article is online at http://ccforum.com/content/12/4/169

(c) 2008 BioMed Central Ltd

See related research by Payen et al., http://ccforum.com/content/12/3/R74
Critical Care 2008, 12:169 (doi:10.1186/cc6948)

\begin{abstract}
Fluid therapy is fundamental to the acute resuscitation of critically ill patients. In general, however, early and appropriate goal-directed fluid therapy contributes to a degree of fluid overload in most if not all patients. Recent data imply that a threshold may exist beyond which, after acute resuscitation, additional fluid therapy may cause harm. In patients with acute kidney injury and/or oliguria, a positive fluid balance is almost universal. Few studies have examined the impact of fluid balance on clinical outcomes in critically ill adults with acute kidney injury. Payen and coworkers, in a secondary analysis of the SOAP (Sepsis Occurrence in Acutely III Patients) study, now present evidence that there is an independent association between mortality and positive fluid balance in a cohort of critically ill patients with acute kidney injury. In this commentary, we discuss these findings within the context of prior literature and propose that assessment of fluid balance should be considered as a potentially valuable biomarker of critical illness.
\end{abstract}

\section{Introduction}

Acute kidney injury (AKI) is common [1], increasingly encountered [2] and known to contribute to increased shortterm and long-term morbidity and mortality $[1,3]$. Few if any interventions are proven to alter the clinical course and outcome of $\mathrm{AKI}$ once it is established. Thus, conventional management has been largely supportive, with a focus on averting complications and allowing renal recovery to occur. Clinical management surveys have found the manner of 'supportive' care for the critically ill patient with AKI to be variable among practitioners [4]. Moreover, many of the supportive therapies available, including fluid administration, diuretic use and extracorporeal renal replacement (RRT), are highly context specific.
Fluid therapy, in particular, is integral to the acute resuscitation of critically ill patients and is probably the only effective strategy in terms of preventing AKI. Practically all patients receive variable amounts of fluid therapy during an episode of critical illness. There is consensus that fluids should be given early and targeted to appropriate physiologic end-points. The concept of early goal-direct therapy as a guide for acute resuscitation in septic shock was considered ground breaking [5]. Notably, in this trial, by 72 hours all enrolled patients had received 13 to 14 I fluid therapy. No specific data were provided on the occurrence of AKI, oliguria, or fluid balance. However, the septic patient is known to be at high risk for $\mathrm{AKI}$, and so a high incidence was probable [6]. In this context, AKI contributes to impaired free water and solute excretion, and almost universally translates into fluid accumulation. In fact, a degree of fluid overload is more the rule than exception in the septic patient. However, a threshold may exist beyond which the perceived benefit of additional fluid therapy (or accumulation) after resuscitation may contribute to harm $[1,7,8]$.

We contend that the assessment of fluid balance should be regarded a potentially valuable biomarker of critical illness. In a small retrospective study of 36 patients with septic shock, Alsous and coworkers [7] identified higher mortality in those not achieving a negative fluid balance in at least one of the first 3 days after intensive care unit (ICU) admission. The impact of maintaining a neutral or negative fluid balance has been shown to improve outcomes in acute lung injury [9] and pulmonary oedema [10], and it is predictive of successful weaning from mechanical ventilation [11]. In a cohort of

$\mathrm{AKI}=$ acute kidney injury; CRRT = continuous renal replacement therapy; $\% \mathrm{FO}=$ percentage fluid overload; ICU $=$ intensive care unit; RRT $=$ renal replacement therapy. 
septic patients with $\mathrm{AKI}$, Van Biesen and colleagues [8] showed that additional fluid therapy (despite apparent optimal haemodynamics, restoration of intravascular volume and a high rate of diuretic use) not only failed to improve kidney function but also led to unnecessary fluid accumulation and impaired gas exchange.

There is an abundance of small clinical studies of critically ill children with AKI that have identified degree of fluid overload to be an independent variable associated with mortality [12-15]. Goldstein and coworkers [14] evaluated 21 children with $\mathrm{AKI}$ and found a higher percentage fluid overload (\%FO; calculated as [(total fluid in - total fluid out)/admission body weight $\times 100$ ]) at the time of initiation of continuous RRT (CRRT) to be associated with lower survival, independent of severity of illness. This finding was further confirmed in two additional investigations (one retrospective single centre study and one prospective observational multicentre study) of critically ill children with multiple organ dysfunction syndrome and $\mathrm{AKI}[12,15]$. In another retrospective review, Gillespie and coworkers [13] found that \%FO above $10 \%$ at CRRT initiation was independently associated with mortality (hazard ratio $=3.02,95 \%$ confidence interval $=1.5$ to $6.1 ; P=0.002$ ). In recent surveillance of 51 children receiving stem cell transplantation whose course was complicated by ICU admission and AKI [16], CRRT was initiated in $88 \%$ for management of fluid overload (average \%FO at initiation was $12.4 \%$ ). These data strongly support the view that there is a survival benefit from early initiation of CRRT to prevent fluid accumulation and overload in critically ill children, once initial fluid resuscitative management has been accomplished.

Few clinical investigations, until now, have evaluated the impact that fluid balance has on clinical outcomes in critically ill adults with AKI [1]. In a secondary analysis of the SOAP (Sepsis Occurrence in Acutely III Patients) study, Payen and colleagues [1] examined the influence of fluid balance on survival of critically ill patients with AKI. In this study, patients were compared by whether they developed AKI, defined by a renal Sequential Organ Failure Assessment score of 2 or greater, or by urine output under $500 \mathrm{ml} /$ day. Of the 3,147 patients enrolled, 1,120 (36\%) developed AKI, with $75 \%$ of episodes occurring within 2 days of ICU admission. Mortality at 60 days was higher for those with $\mathrm{AKI}$ (36\% versus 16\%; $P<0.01)$. In patients with both early and late onset $\mathrm{AKI}$, average daily fluid balance through the first 7 ICU days was significantly more positive than in non-AKI patients $(P<0.05$ for each day). Similarly, average daily fluid balance was significantly more positive in those with oliguria $(620 \mathrm{ml}$ versus $270 \mathrm{ml} ; P<0.01)$ and those receiving RRT $(600 \mathrm{ml}$ versus $390 \mathrm{ml} ; P<0.001)$. Average daily fluid balance was significantly higher in nonsurvivors than in survivors $(1,000 \mathrm{ml}$ versus $150 \mathrm{ml} ; P<0.001)$. On multivariable analysis, a positive fluid balance (per 1/24 hours) exhibited an independent association with 60-day mortality (hazard ratio $=$ $1.21,95 \%$ confidence interval $=1.13$ to $1.28 ; P<0.001)$.
Although no data were available on fluid balance by timing of RRT, those receiving earlier RRT $(<2$ days after ICU admission) had lower 60-day mortality (44.8\% versus $64.6 \%$; $P<0.01)$, despite more oliguria and greater severity of illness.

Naturally, such observational data have limitations, and the observed associations are prone to bias from selection, confounding and random error. However, these data, along with those from prior studies, provide compelling evidence that attention to fluid balance and prevention of volume overload, in particular in AKI, may be an important and underappreciated determinant of survival.

These data encourage speculation that one benefit of early RRT, when defined by the duration of time after ICU admission (independent of the severity of AKI), may be early prevention or control of fluid overload [17]. Moreover, this would suggest that prevention or management of fluid overload is evolving as a primary trigger/indicator for extracorporeal fluid removal, and this may be independent of dose delivery or solute clearance. This concept is also supported by the recent ATN (Acute Renal Failure Trial Network) trial [18], in which patients allocated to alternate-day, less-intensive haemodialysis not uncommonly had inadequate fluid volume control necessitating additional 'off-protocol' ultrafiltration sessions.

The accrued evidence implies, at least following initial resuscitation, that attention to fluid balance has clinical relevance. We may need a paradigm shift in how we currently apply RRT. Rather than the conventional view as rescue therapy (fluid overload associated with pulmonary oedema), we must consider early RRT in order to counterbalance fluid accumulation, particularly in those with oliguria or AKI.

Timing is crucial, and RRT should ideally be initiated as early and safely as possible [19]. As a minimum, all critically ill patients should have an estimate of baseline 'dry' weight and determination of the iatrogenic daily and cumulative fluid load and balance [20]. Estimation of 'dry' weight can be problematic in the critically ill, and a clear priority for early RRT in critically ill patients would be to ensure maintenance of an adequate circulating blood volume and prevent unnecessary complications during fluid removal. Clearly, we need additional research to define the boundaries of fluid balance as a biomarker of critical illness that may portend improvements in clinical management and outcomes.

\section{Competing interests}

The author(s) declare that they have no competing interests.

\section{References}

1. Payen D, de Pont AC, Sakr Y, Spies C, Reinhart K, Vincent JL: A positive fluid balance is associated with a worse outcome in patients with acute renal failure. Crit Care 2008, 12:R74. 
2. Bagshaw SM, George C, Bellomo R: Changes in the incidence and outcome for early acute kidney injury in a cohort of Australian intensive care units. Crit Care 2007, 11:R68.

3. Hoste EA, Schurgers M: Epidemiology of acute kidney injury: how big is the problem? Crit Care Med 2008, 36:S146-S151.

4. Ricci Z, Ronco C, D'Amico G, De Felice R, Rossi S, Bolgan I, Bonello M, Zamperetti N, Petras D, Salvatori G, Dan M, Piccinni $P$ : Practice patterns in the management of acute renal failure in the critically ill patient: an international survey. Nephrol Dial Transplant 2006, 21:690-696.

5. Rivers E, Nguyen B, Havstad S, Ressler J, Muzzin A, Knoblich B, Peterson E, Tomlanovich M: Early goal-directed therapy in the treatment of severe sepsis and septic shock. N Engl J Med 2001, 345:1368-1377.

6. Bagshaw SM, George C, Bellomo R: Early acute kidney injury and sepsis: a multicentre evaluation. Crit Care 2008, 12:R47.

7. Alsous $F$, Khamiees M, DeGirolamo A, Amoateng-Adjepong $Y$, Manthous CA: Negative fluid balance predicts survival in patients with septic shock: a retrospective pilot study. Chest 2000, 117:1749-1754.

8. Van Biesen W, Yegenaga I, Vanholder R, Verbeke F, Hoste E, Colardyn $\mathrm{F}$, Lameire N: Relationship between fluid status and its management on acute renal failure (ARF) in intensive care unit (ICU) patients with sepsis: a prospective analysis. J Nephrol 2005, 18:54-60.

9. Wiedemann HP, Wheeler AP, Bernard GR, Thompson BT, Hayden D, deBoisblanc B, Connors AF Jr, Hite RD, Harabin AL: Comparison of two fluid-management strategies in acute lung injury. N Engl J Med 2006, 354:2564-2575.

10. Mitchell JP, Schuller D, Calandrino FS, Schuster DP: Improved outcome based on fluid management in critically ill patients requiring pulmonary artery catheterization. Am Rev Respir Dis 1992, 145:990-998.

11. Upadya A, Tilluckdharry L, Muralidharan V, Amoateng-Adjepong $Y$, Manthous CA: Fluid balance and weaning outcomes. Intensive Care Med 2005, 31:1643-1647.

12. Foland JA, Fortenberry JD, Warshaw BL, Pettignano R, Merritt RK, Heard ML, Rogers K, Reid C, Tanner AJ, Easley KA: Fluid overload before continuous hemofiltration and survival in critically ill children: a retrospective analysis. Crit Care Med 2004, 32: 1771-1776.

13. Gillespie RS, Seidel K, Symons JM: Effect of fluid overload and dose of replacement fluid on survival in hemofiltration. Pediatr Nephrol 2004, 19:1394-1399.

14. Goldstein SL, Currier H, Graf C, Cosio CC, Brewer ED, Sachdeva $\mathrm{R}$ : Outcome in children receiving continuous venovenous hemofiltration. Pediatrics 2001, 107:1309-1312.

15. Goldstein SL, Somers MJ, Baum MA, Symons JM, Brophy PD, Blowey D, Bunchman TE, Baker C, Mottes T, McAfee N, Barnett J, Morrison G, Rogers K, Fortenberry JD: Pediatric patients with multi-organ dysfunction syndrome receiving continuous renal replacement therapy. Kidney Int 2005, 67:653-658.

16. Flores FX, Brophy PD, Symons JM, Fortenberry JD, Chua AN, Alexander SR, Mahan JD, Bunchman TE, Blowey D, Somers MJ, Baum M, Hackbarth R, Chand D, McBryde K, Benfield M, Goldstein SL: Continuous renal replacement therapy (CRRT) after stem cell transplantation. A report from the prospective pediatric CRRT Registry Group. Pediatr Nephrol 2008, 23:625-630.

17. Bagshaw SM, Uchino S, Bellomo R, Morimatsu H, Morgera S, Schetz M, Tan I, Bouman C, Macedo E, Gibney N, Tolwani A, Oudemans-van Straaten HM, Ronco C, Kellum JA, for the Beginning and Ending Supportive Therapy for the Kidney (BEST Kidney) Investigators: Timing of renal replacement therapy and clinical outcomes in critically ill patients with severe acute kidney injury. J Crit Care 2008 [Epub ahead of print].

18. The VA/NIH Acute Renal Failure Trial Network: Intensity of renal support in critically ill patients with acute kidney injury. $N$ Engl $J$ Med 2008, 359:7-20.

19. Ronco C: Early goal directed therapy and early goal ultrafiltration therapy for critically ill patients with acute kidney injury. Int J Artif Organs 2004, 27:911-912.

20. Ronco C: The 'right' weight of patients in hemodialysis: dry you fly and wet you die or dry you're down and wet you're up and around? Int J Artif Organs 2004, 27:81-82. 